\title{
Polymerization-Induced Self-Assembly Promoted by Liquid-Liquid Phase Separation
}

\author{
Yi Ding, Qingqing Zhao, Lei Wang, Leilei Huang, Qizhou Liu, Xinhua Lu, and Yuanli Cai*
}

State-Local Joint Engineering Laboratory for Novel Functional Polymer Materials, College of Chemistry, Chemical Engineering and Materials Science, Soochow University, Suzhou 215123, China

\section{Supporting Information}

Materials. Poly(2-hydroxypropyl methacrylamide) $\left(\right.$ PHPMA $_{44}$ macro-CTA; ${ }^{1} \mathrm{H}$ NMR: DP $=44 ;$ DMF SEC: $M_{\mathrm{n}}=5.8 \mathrm{~kg} / \mathrm{mol}$, $Ð=1.15)$ was synthesized previously. ${ }^{1}$ Synthesis and chain-end protection of poly(2-acrylamido-2-methylpropanesulfonic acid) (PAMPS $_{50}:{ }^{1} \mathrm{H}$ NMR: DP = 50; SEC: $M_{\mathrm{n}}=11.5 \mathrm{~kg} / \mathrm{mol}, D=1.19$; PAMPS $_{98}:{ }^{1} \mathrm{H}$ NMR: DP = 98; SEC: $M_{\mathrm{n}}=20.1 \mathrm{~kg} / \mathrm{mol}, D=$ 1.18; PAMPS $_{150}:{ }^{1} \mathrm{H}$ NMR: DP = 150; SEC: $M_{\mathrm{n}}=28.7 \mathrm{~kg} / \mathrm{mol}, D=1.16$ ) were described elsewhere. ${ }^{2}$ Sodium phenyl-2,4,6-trimethylbenzoylphosphinate (SPTP) initiator was synthesized according to patented method. ${ }^{3}$ 2-Acrylamido-2-methylpropanesulfonic acid (AMPS) monomer, linear polyethylenimine $\left(\mathbf{P E I}_{232}: M_{\mathrm{n}}=10.0 \mathrm{~kg} / \mathrm{mol}, \mathrm{DP}=232, Ð \leq 1.2 ; \mathrm{pKa}=8.4 \text {, Figure } \mathrm{Si}\right)^{4}$ were purchased from Sigma-Aldrich. Deuterium oxide $\left(\mathrm{D}_{2} \mathrm{O}, 99.8 \% \mathrm{D}\right)$ and deuterchloric acid $\left(20 \% \mathrm{DCl}\right.$ in $\left.\mathrm{D}_{2} \mathrm{O}, 99.5 \% \mathrm{D}\right)$ from Adamas; other agents from Aladdin; these agents were used as received. Fresh deionized water was obtained from a Direct-Q 5 UV Millipore system and used for the synthesis and characterization.

PEI $_{232} /$ PAMPS $_{98}$ Coacervate. PAMPS $_{98}$ (o.56 g, 2.45 mmol PAMPS unit), PEI $_{232}$ (o.10 g, 2.45 mmol PEI unit) were added into water $(3.47 \mathrm{~g})$ in a $10 \mathrm{~mL}$ vial and stirred for $1 \mathrm{~h}$. The mixture was concentrated to $0.73 \mathrm{~g}$, moved to a $2 \mathrm{~mL}$ vial and added water $(0.37 \mathrm{~g})$ to $60 \% \mathrm{w} / \mathrm{w}$ solids. Solution separated to polymer-poor solution and polymer-rich complex coacervate phase. Viscous coacervate could flow slowly down onto glass slide. To elucidate successful PIC, $\mathrm{NaCl}$ was dissolved in the solution to $4.5 \mathrm{M} \mathrm{NaCl}$. Transparent solution was studied by DLS. Coacervates were freeze-dried, solids were dissolved in $\mathrm{D}_{2} \mathrm{O}$ and $4.5 \mathrm{M} \mathrm{NaCl}$ ( $\mathrm{pH}$ 2.0) for ${ }^{1} \mathrm{H}$ NMR analysis. $\mathrm{PAMPS}_{50} / \mathrm{PEI}_{232}$ and $\mathrm{PAMPS}_{150} / \mathrm{PEI}_{232}$ were prepared under above conditions.

PIESA Synthesis of $\mathbf{H}_{44} \mathbf{A}_{97} / \mathbf{E}_{232}$ Coacervate Droplets $\left(\mathbf{H}_{44} \mathbf{A}_{97}: \mathbf{P H P M A}_{44}-\mathbf{P A M P S}_{97}, \mathbf{E}_{232}: \mathbf{P E I}_{232}\right)$ ). AMPS monomer (o.1153 g, $0.557 \mathrm{mmol}$ ), PHPMA $_{44}$ macro-CTA (37.8 mg, $\left.2.4 \mu \mathrm{mol}\right)$, PEI $_{232}$ (24.0 mg, $0.557 \mathrm{mmol}$ PEI unit) and water (0.9298 g) were added into a $5 \mathrm{~mL}$ flask. The solution was adjusted to $\mathrm{pH} 2.0$. SPTP initiator ( $18.6 \mathrm{mg}, 1.0 \% \mathrm{w} / \mathrm{w}$ in water, $0.6 \mu \mathrm{mol}$ ) was added in the flask. The flask was immersed in a water bath at $25^{\circ} \mathrm{C}$, bubbled with argon for $1 \mathrm{~h}$, and irradiated with visible light for $4 \mathrm{~h}$. Reaction was stopped by exposure to air. Other droplets were synthesized under above conditions, maintaining $16 \% \mathrm{w} / \mathrm{w}$ solids and $n^{-} / n^{+}=[\text {AMPS }]_{\circ} /[\text { PEI unit }]_{0}=1.0$, changing AMPS/PHPMA ${ }_{44}$ (and irradiation time) to $33(8 \mathrm{~h}), 58(6.5 \mathrm{~h})$, 77 (6 h), 86 (6 h), 116 (4 h) and 154 (4 h). Final solution was studied using ${ }^{1} \mathrm{H}$ NMR, SEC, $\zeta$-potential, DLS, optical microscopy, TEM, AFM, without further purification.

PIESA Kinetics of $\mathbf{H}_{44} \mathbf{A}_{97} / \mathbf{E}_{232}$ Coacervate Droplets. PIESA formulation and reaction conditions are the same as described above. The solution was sampled periodically using a deoxygenated syringe. The reaction was stopped by exposed to air. The sample vial was wrapped by aluminum foil prior to ${ }^{1} \mathrm{H}$ NMR, SEC, $\zeta$-potential, DLS, optical microscopy and TEM studies, without further purification.

Osmotic Deswelling by Adding Ethanol. Typically, PAMPS ${ }_{50} / \mathrm{PEI}_{232}$ coavervate was used to study deswelling behavior. Polymer-poor solution phase was replaced with equal volume mixture of ethanol and water $(1: 1, \mathrm{w} / \mathrm{w})$. The supernatant was removed after 1 day. Stiffened sample was taken out of the vial, cut to square shape, immersed in ethanol/water (1:1, w/w) overnight. The deswelling of $\mathrm{H}_{44} \mathrm{~A}_{33} / \mathrm{E}_{232}$ coacervate droplets upon adding ethanol into the aqueous solution was studied as follows. The solution ( $16 \%$ solids, $30 \mu \mathrm{L})$ was diluted in ethanol/water (1:1, w/w, $2.4 \mathrm{~mL})$. Nanostructures were visualized using TEM analysis of the freeze-dried sample.

PIESA Synthesis of Nanostructured $\mathbf{H}_{44} \mathbf{A}_{125} / \mathbf{E}_{232}$ PICs in 1:1 Ethanol/Water. AMPS monomer (0.2498 g, $\left.1.206 \mathrm{mmol}\right)$, PHPMA $_{44}$ macro-CTA $(58.4 \mathrm{mg}, 8.9 \mu \mathrm{mol})$ and PEI $_{232}(52.4 \mathrm{mg}$, $1.206 \mathrm{mmol}$ PEI unit) were dissolved in ethanol/water (1:1, $\mathrm{w} / \mathrm{w} ; 0.32 \mathrm{~g}$ ) in a $5 \mathrm{~mL}$ flask. SPTP initiator $(41.1 \mathrm{mg}, 1.0 \% \mathrm{w} / \mathrm{w}$ in water; $1.30 \mu \mathrm{mol})$ was added into the flask. The flask was immersed into a water bath at $25^{\circ} \mathrm{C}$, bubbled with argon for $1 \mathrm{~h}$, and irradiated with visible light for $2.5 \mathrm{~h}$. The reaction was stopped by exposure to air. Other nanoparticles were synthesized under above conditions maintaining 50\% w/w solids and $n^{-} / n^{+}=1.0$, changing AMPS/PHPMA 44 (and irradiation time) to $30(5 \mathrm{~h}), 58(3 \mathrm{~h}), 85(3 \mathrm{~h}), 145(2.5 \mathrm{~h})$, and $154(2.5 \mathrm{~h})$. The final solution was studied by ${ }^{1} \mathrm{H}$ NMR, aqueous SEC, $\zeta$-potential, DLS, and TEM without further purification.

Instrumentation. Visible light at $\mathrm{I}_{420} \mathrm{~nm}=0.20 \mathrm{~mW} / \mathrm{cm}^{2}$ was obtained from a home-made photoreaction system consisting of a mercury lamp, a JB40o filter, a ventilator and a $420 \mathrm{~nm}$ detector. The polymer products were freeze-dried in a Labconco Freezone2.5L freeze-drier. The $\mathrm{pH}$ value was probed by OHAUS ST310o digital $\mathrm{pH}$-meter. 
Characterization. ${ }^{1} \mathrm{H} N M R$ spectra were recorded on an INOVA $400 \mathrm{MHz}$ NMR instrument. $N$, $N$-dimethylformamide (DMF) Size exclusion chromatography (DMF SEC) was conducted on PL-GPC220 integrated system equipped with refractive index detector and GPC column set (2×PL-Gel MIXED-B + 1×PL-Gel MIXED-D). DMF eluent (10.0 mM LiBr) and PMMA standards (Agilent, $1.95-1048.0 \mathrm{~kg} / \mathrm{mol}$ ) were used. The calibration and analysis proceeded at a $1.0 \mathrm{~mL} / \mathrm{min}$ flow rate at $80^{\circ} \mathrm{C}$. Sample solution was filtered using a Millipore Millex-FG $0.2 \mu \mathrm{m}$ filter before DMF SEC studies. Aqueous SEC was performed on a Waters1515 GPC setup equipped with refractive index detector and a column set (2×PL Aquagel-OH Mixed-M). Columns were eluted by the degassed buffer (o.20 $\mathrm{M} \mathrm{NaNO}_{3}+0.01 \mathrm{M} \mathrm{Na}_{2} \mathrm{HPO}_{4}$, $\mathrm{pH}$ 9.0). PEG standards (Agilent, $17.8-692.0 \mathrm{~kg} / \mathrm{mol}$ ) were used for calibration. The calibration and analysis were conducted at a $1.0 \mathrm{~mL} / \mathrm{min}$ flow rate at $30{ }^{\circ} \mathrm{C}$. Block copolymer was dissociated from the droplet in the buffer adjusted to $\mathrm{pH}$ 9.5, and filtered using $0.2 \mu \mathrm{m}$ Supor filter to remove deionized $\mathrm{PEI}_{232}$ precipitates prior to aqueous SEC studies. Dynamic light scattering (DLS) was performed on a Brookhaven BI-20oSM setup equipped with $22 \mathrm{~mW}$ He-Ne laser, BI-200SM goniometer and BI-TurboCorr digital correlator. Solution was diluted to $2.0 \mathrm{mg} / \mathrm{mL}$ and adjusted to $\mathrm{pH} 2.0$ prior to DLS studies. Otherwise mentioned, the sample was measured at a $90^{\circ}$ angle at $25^{\circ} \mathrm{C}$. Data were evaluated by cumulants analysis in CONTIN routine and averaged over 5 runs. $\zeta$-Potential was probed using a Malvern Zetasizer Nano-ZSgo instrument and data were averaged over five runs. Bright-field optical microscopy was performed on an OLYMPUS IX 73 to identify the microdroplets. In all these cases, the complex coacervates appeared as spherical droplets in solution. Transmission electron microscopy (TEM) was performed on a Hitachi HT77oo transmission electron microscope at an accelerating voltage of $100 \mathrm{kV}$. The solution $(2.0 \mathrm{mg} / \mathrm{mL})$ was dripped onto a carbon film coated copper grid, frozen in liquid nitrogen to $-170{ }^{\circ} \mathrm{C}$ in a home-made cryo-box, and freeze-dried under reduced pressure. The mean diameter $\left(D_{\mathrm{n}}\right)$ and the dispersity (PDI) was obtained by statistical analysis from $>300$ particles using Nano Measurer 1.2 software. Atomic force microscopy (AFM) was conducted on a Bruker Multimode 8 microscope operated in a peak force quantitative nanomechanical mode using a SCANASYST-AIR probe. Silicon wafer was immersed into piranha solution at $80{ }^{\circ} \mathrm{C}$ for $1.5 \mathrm{~h}$, rinsed with anhydrous ethanol under ultrasonic irrigation. Sample was prepared under TEM sample preparation conditions, using cleaned silicon wafer and diluted solution $\left(0.2 \mathrm{mg} / \mathrm{mL}\right.$ in cold water, $\left.\mathrm{o}^{\circ} \mathrm{C}, \mathrm{pH} 2.0\right)$.

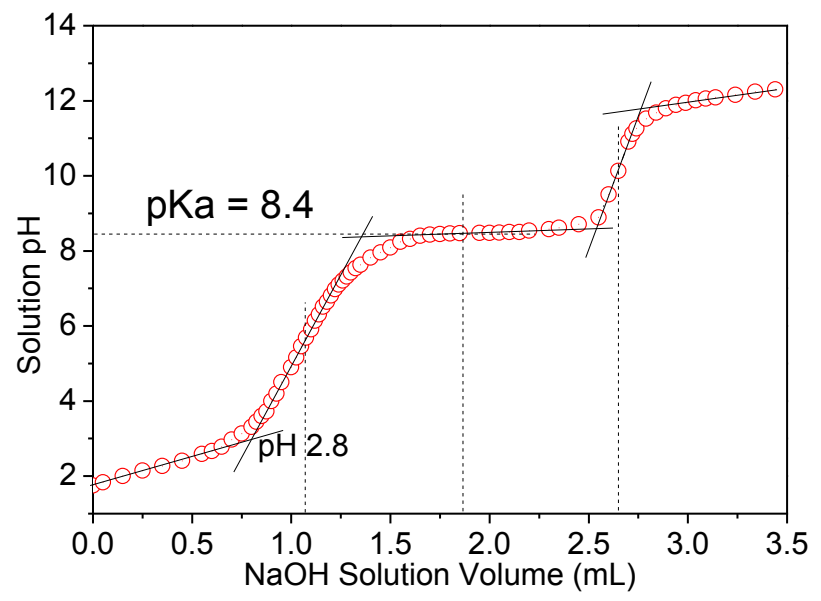

Figure S1. Potentiometric titration plots of the linear $\mathrm{PEI}_{232}(0.30 \mathrm{M}$ in water at $\mathrm{pH}$ 1.8) using o.20 $\mathrm{M} \mathrm{NaOH}$ titrant.

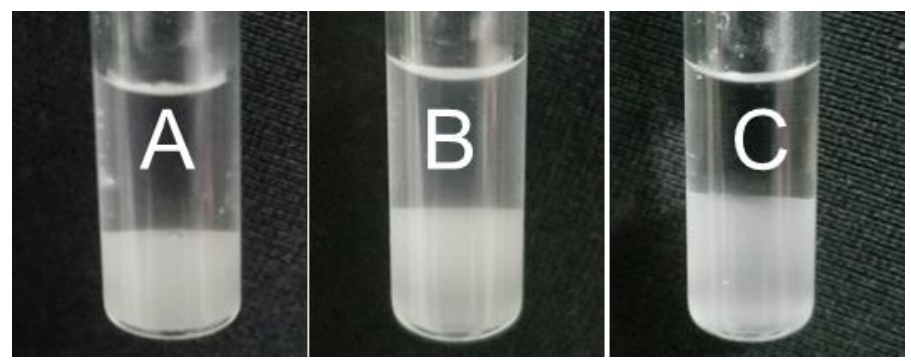

Figure S2. Photographs of (A) $A_{50} / E_{232}$, (B) $A_{98} / E_{232}$, (C) $A_{150} / E_{232}$ (A: PAMPS, E: PEI, number: DP) formed by mixing PAMPS with $\mathrm{PEI}_{232}$ at $n^{-} / n^{+}=1.0$ ( $n^{-}$: PAMPS unit, $n^{+}$: PEI unit) in water at $\mathrm{pH} 2.0$ and concentrating to $60 \% \mathrm{w} / \mathrm{w}$ total solids content. 


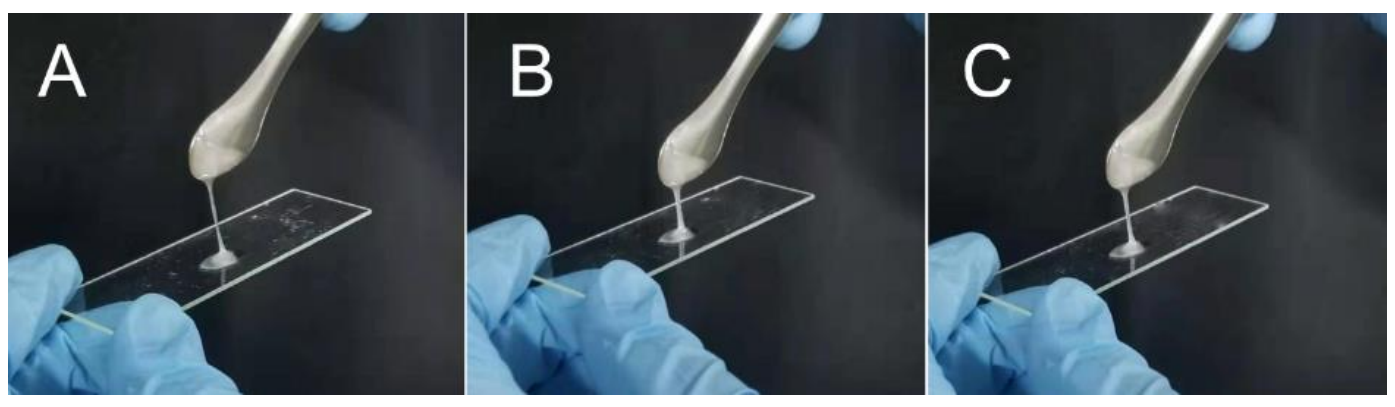

Figure $S_{3}$. Photographs of $(\mathbf{A}) \mathrm{A}_{50} / \mathrm{E}_{232},(\mathbf{B}) \mathrm{A}_{98} / \mathrm{E}_{232},(\mathbf{C}) \mathrm{A}_{150} / \mathrm{E}_{232}$ coacervates shown in Figure S2, in which slowly flowing character illustrates the fluidic nature of the $A_{x} / E_{232}(x=50-150)$ complex coacervates.
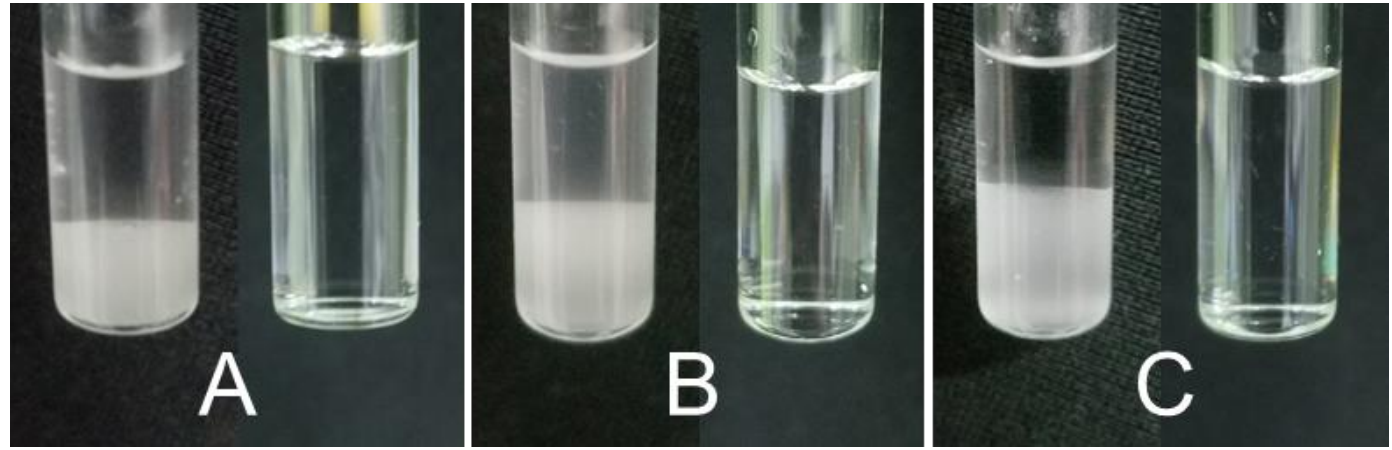

Figure S4. Photographs of (A) $\mathrm{A}_{50} / \mathrm{E}_{232},(\mathbf{B}) \mathrm{A}_{98} / \mathrm{E}_{232}$, (C) $\mathrm{A}_{150} / \mathrm{E}_{232}$ coacervates before (left) and after (right) dissolving 4.5 $\mathrm{M} \mathrm{NaCl}$ in the aqueous solution.

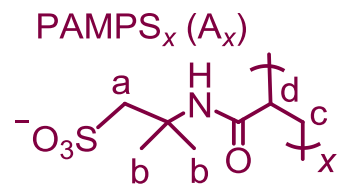

$$
\mathrm{PEI}_{232}\left(\mathrm{E}_{232}\right)
$$
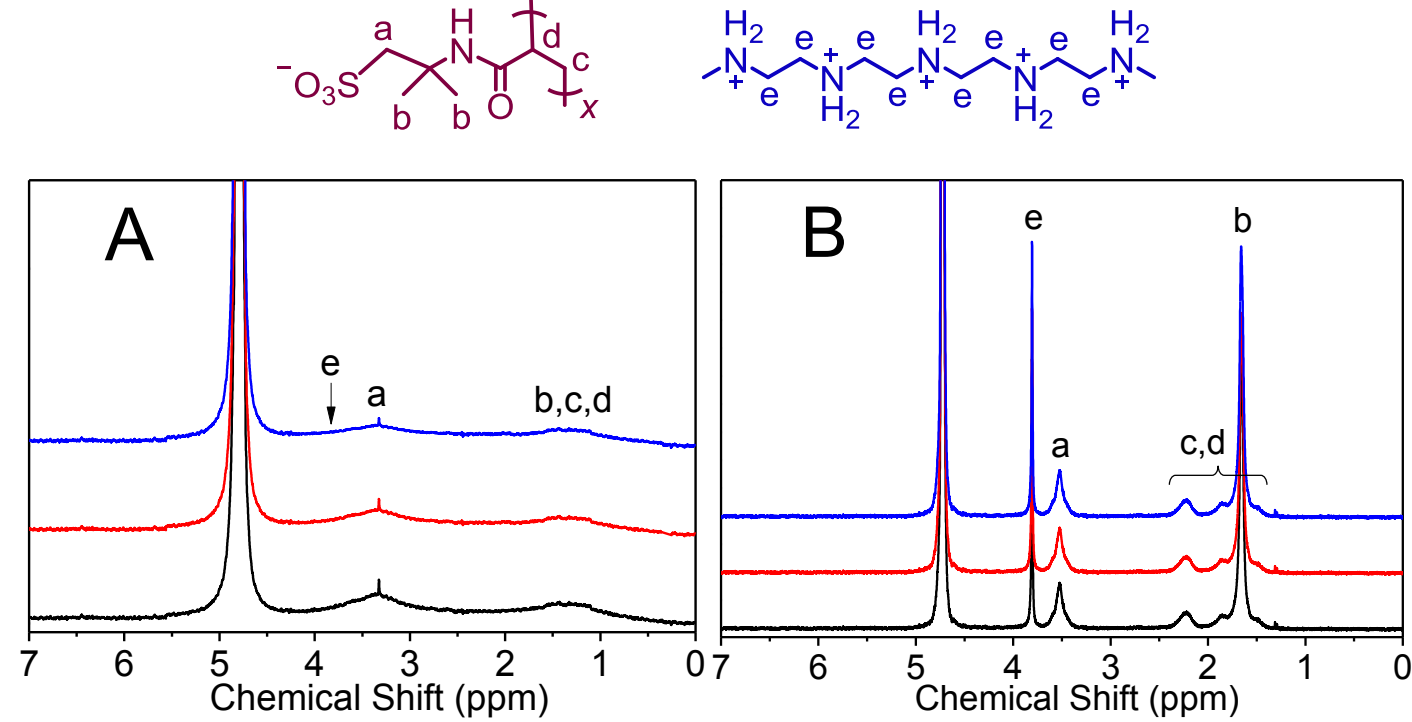

Figure $\mathrm{S}_{5} \cdot{ }^{1} \mathrm{H}$ NMR spectra of (black) $\mathrm{A}_{50} / \mathrm{E}_{232}$, (red) $\mathrm{A}_{98} / \mathrm{E}_{232}$, (blue) $\mathrm{A}_{150} / \mathrm{E}_{232}$ recorded in $(\mathbf{A}) \mathrm{D}_{2} \mathrm{O}$ and $(\mathbf{B}) 4.5 \mathrm{M} \mathrm{NaCl}$ at $\mathrm{pH}$ 2.o. 


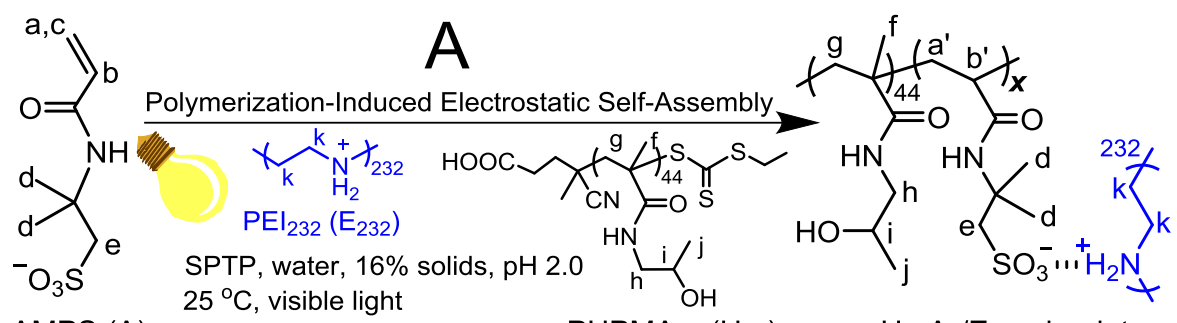

AMPS (A)

$\mathrm{PHPMA}_{44}\left(\mathrm{H}_{44}\right)$

$\mathrm{H}_{44} \mathrm{~A}_{x} / \mathrm{E}_{232}$ droplet
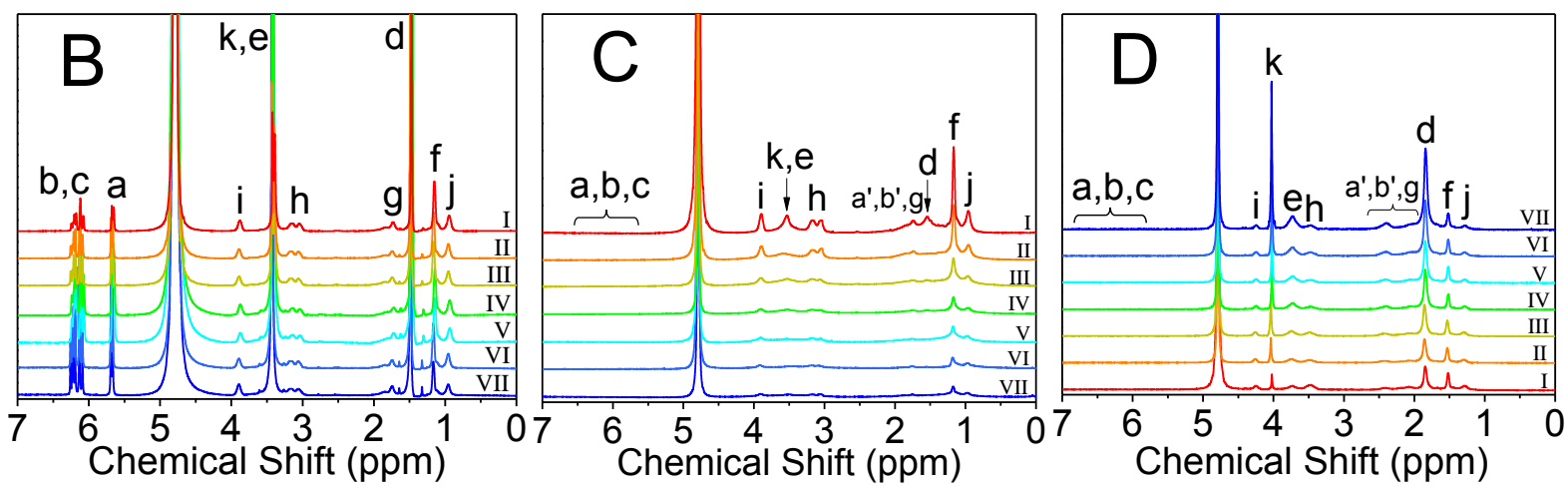

Figure S6. (A) PISA method to synthesize $\mathrm{H}_{44} \mathrm{~A}_{x} / \mathrm{E}_{232}$ coacervate droplets. ${ }^{1} \mathrm{H}$ NMR spectra of (B) the initial solutions and those after polymerization recorded in (C) $\mathrm{D}_{2} \mathrm{O}$, (D) $4.5 \mathrm{M} \mathrm{NaCl}$. Herein, $x=33$ (I), 58 (II), 77 (III), 86 (IV), 97 (V), 116 (VI), 154 (VII).
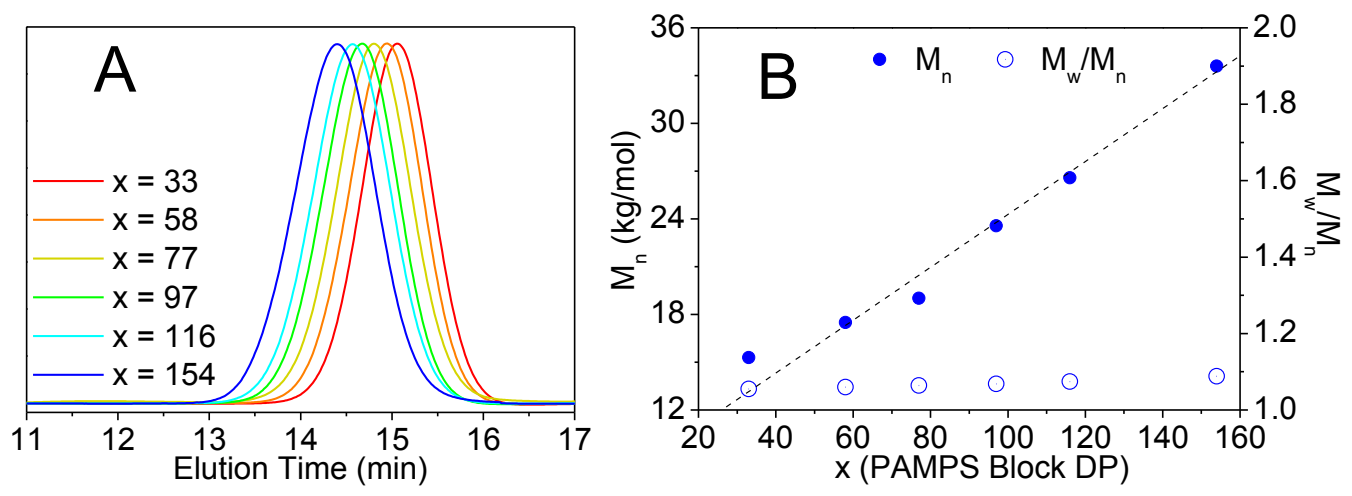

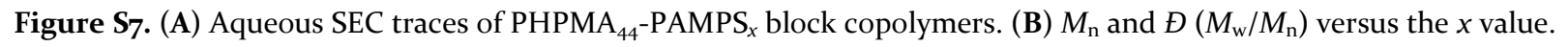

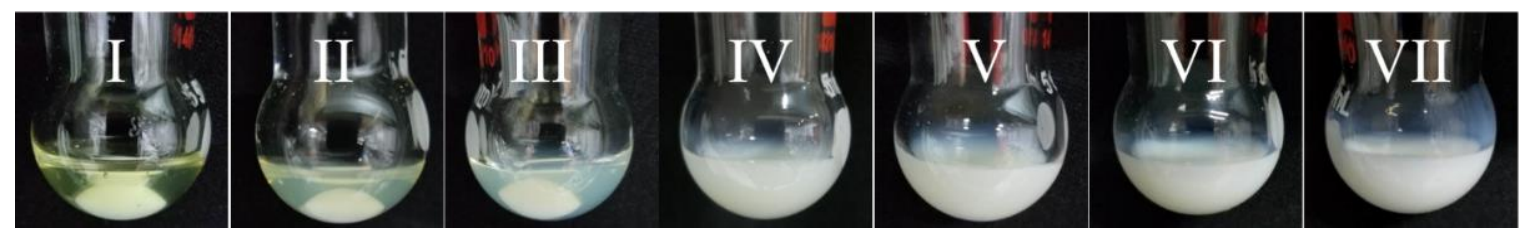

Figure S8. Photographs of the final solutions of $\mathrm{H}_{44} \mathrm{~A}_{x} / \mathrm{E}_{232}$ in which $x=33$ (I), 58 (II), 77 (III), 86 (IV), 97 (V), 116 (VI), 154 (VII).

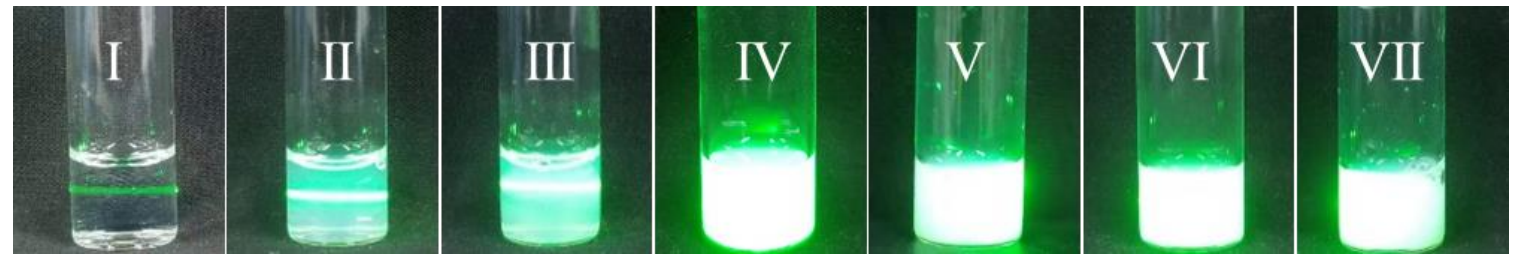

Figure S9. Photographs of diluted $\mathrm{H}_{44} \mathrm{~A}_{x} / \mathrm{E}_{232}$ dispersions (2.0 mg/mL in water at $\left.\mathrm{pH} 2.0\right)$ at $x=33$ (I), 58 (II), 77 (III), 86 (IV), 97 (V), 116 (VI), 154 (VII). 

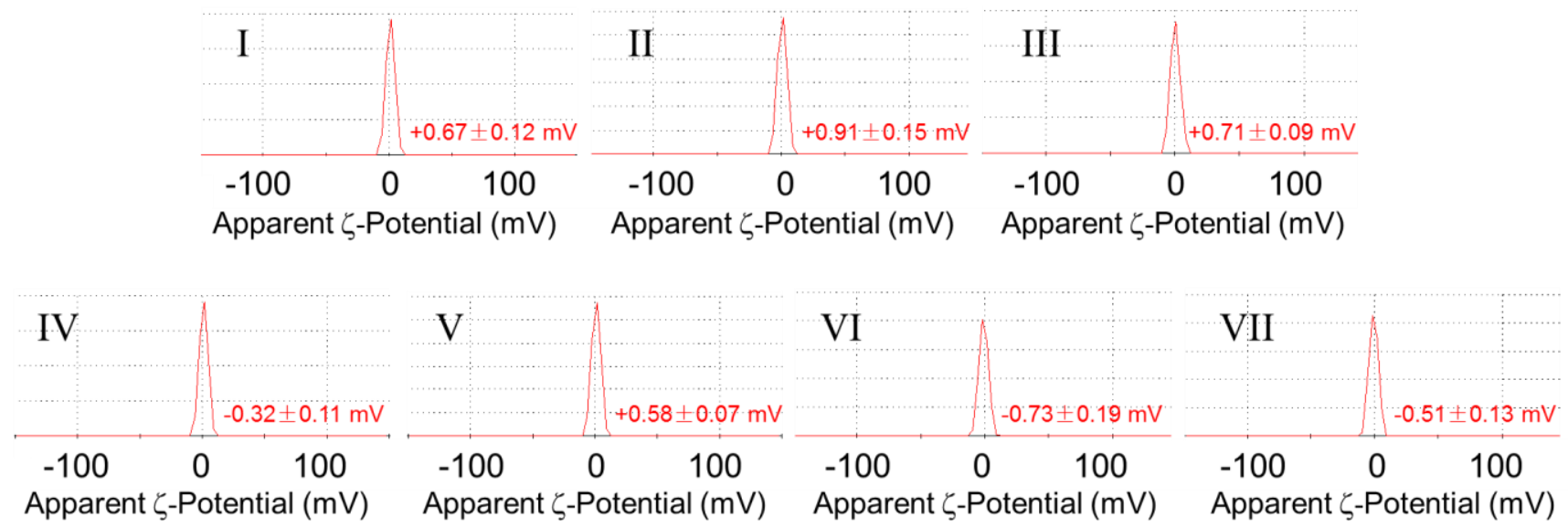

Figure S1o. The $\zeta$-potential results of $\mathrm{H}_{44} \mathrm{~A}_{x} / \mathrm{E}_{232}$ droplets. Herein, $x=33$ (I), 58 (II), 77 (III), 86 (IV), 97 (V), 116 (VI), and 154 (VII).

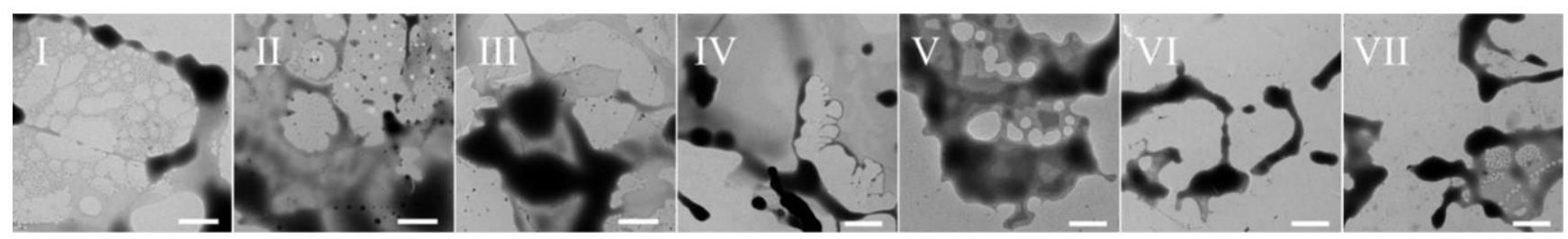

Figure S11. TEM images of room-temperature water evaporated $\mathrm{H}_{44} \mathrm{~A}_{x} / \mathrm{E}_{232}$ droplets, $x=33$ (I), 58 (II), 77 (III), 86 (IV), 97 (V), 116 (VI), 154 (VII). Scale bar $=5 \mu \mathrm{m}$.

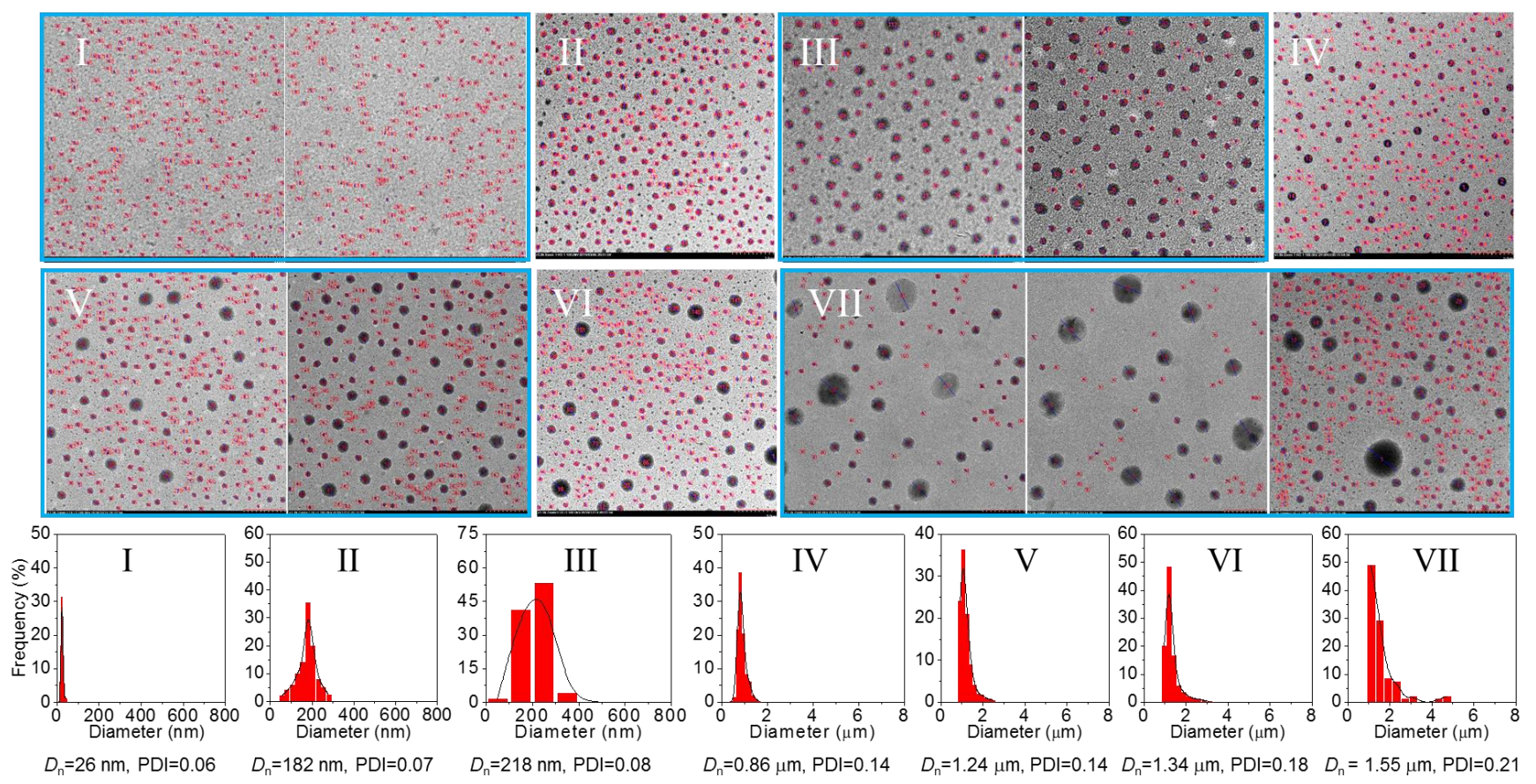

Figure S12. TEM images and statistic results of freeze-dried droplets $\mathrm{H}_{44} \mathrm{~A}_{x} / \mathrm{E}_{232}$ at $x=33$ (I), 58 (II), 77 (III), 86 (IV), 97 (V), 116 (VI), and 154 (VII). Herein, $D_{\mathrm{n}}$ is the number-average diameter of the spheres and PDI is the dispersity in size. 

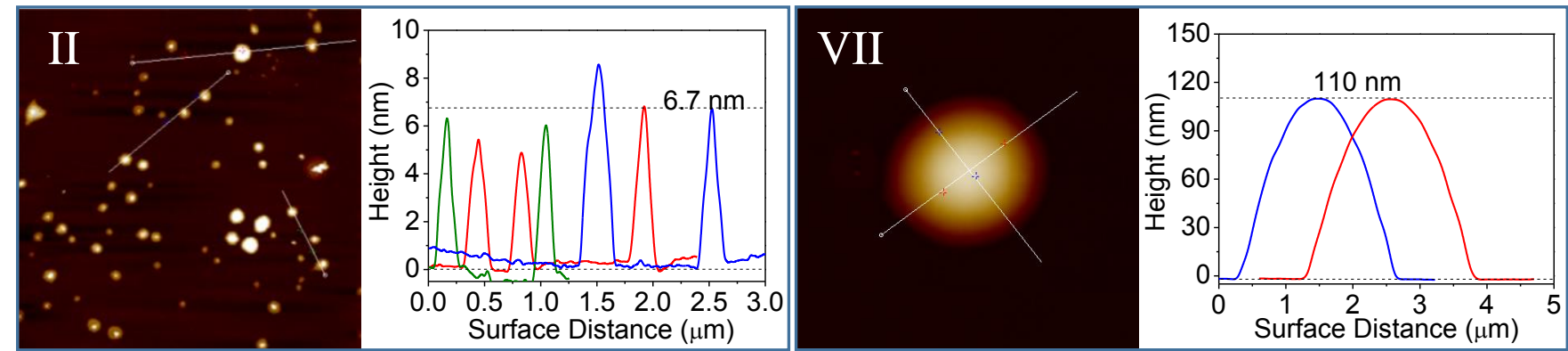

Figure S13. AFM results of freeze-dried (II) $\mathrm{H}_{44} \mathrm{~A}_{58} / \mathrm{E}_{232}$ and (VII) $\mathrm{H}_{44} \mathrm{~A}_{154} / \mathrm{E}_{232}$. Significantly flattened spheres after freeze-drying the inner water molecule are indicated by the diameter-to-height aspect ratios, 41.0 for (II), and 22.3 for (VII).

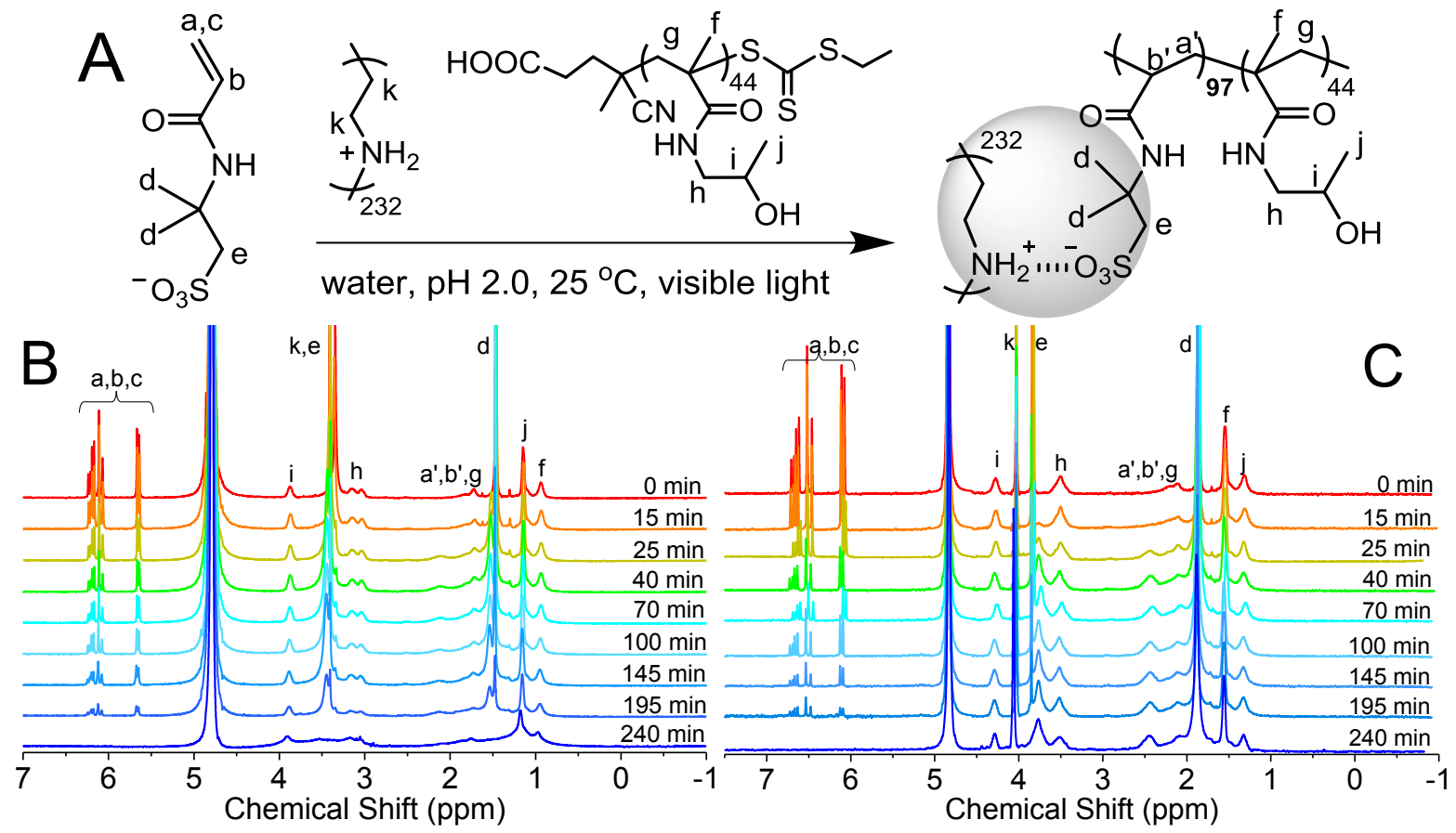

Figure S14. (A) Schematic illustration of PIESA synthesis of $\mathrm{H}_{44} \mathrm{~A}_{97} / \mathrm{E}_{232}$ droplet. ${ }^{1} \mathrm{H}$ NMR spectra at labeled times recorded in (B) $\mathrm{D}_{2} \mathrm{O}$ and (C) $4.5 \mathrm{M} \mathrm{NaCl}$ ( $\mathrm{pH}$ 2.0), in which the monomer conversion was determined using Equation S1:

$$
\text { Conversion }=\left(1-\frac{I_{a, b, c, t}}{I_{a, b, c, 0}} \times \frac{I_{i, 0}}{I_{i, t}}\right) \times 100 \%
$$
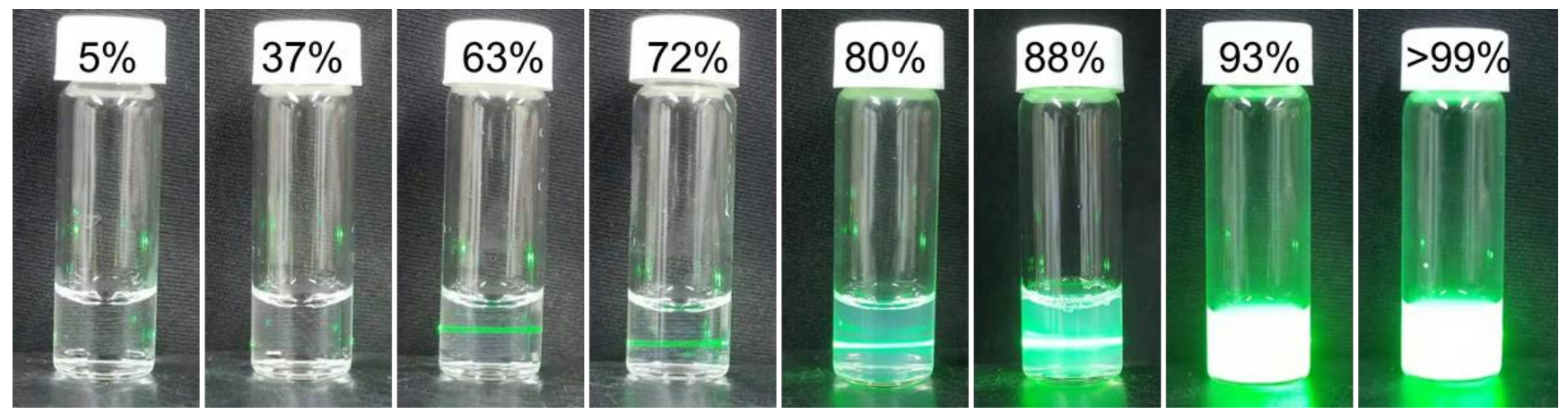

Figure $\mathrm{S}_{15}$. Photographs of diluted solutions $(2.0 \mathrm{mg} / \mathrm{mL}$ in water at $\mathrm{pH}$ 2.0) at labeled conversion in visible light initiated PIESA synthesis of $\mathrm{H}_{44} \mathrm{~A}_{97} / \mathrm{E}_{232}$ microdroplets. 

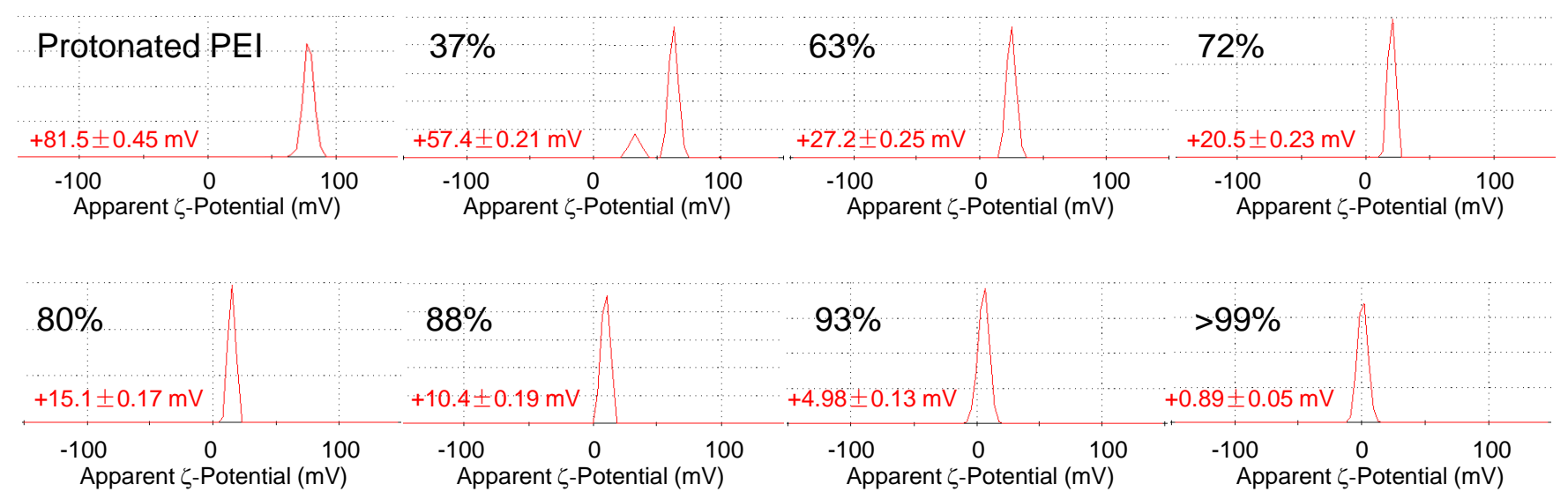

Figure S16. The $\zeta$-potential results of the droplets formed at labeled conversion during visible light initiated PIESA synthesis of $\mathrm{H}_{44} \mathrm{~A}_{97} / \mathrm{E}_{232}$ droplet.
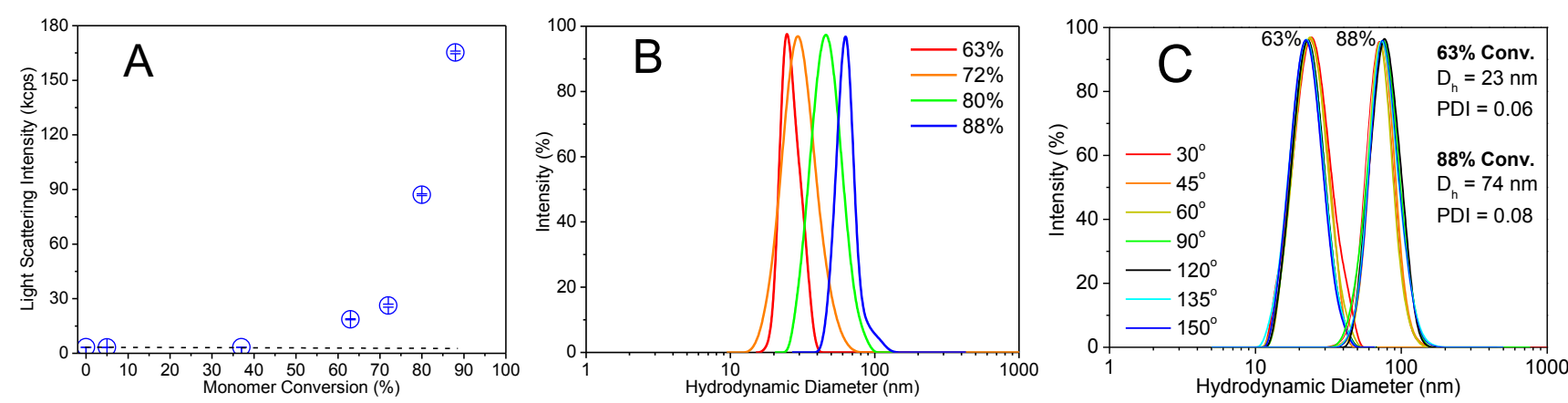

Figure S17. (A) Light scattering intensity and (B) DLS diameter profile of droplets formed during PIESA synthesis of $\mathrm{H}_{44} \mathrm{~A}_{97} / \mathrm{E}_{232}$, recorded at $2.0 \mathrm{mg} / \mathrm{mL}$ in water at $\mathrm{pH}$ 2.0. (C) The diameter profiles of droplets formed at $63 \%$ and $88 \%$ conversions determined at labeled measuring angles.



Figure S18. Optical microscopy images of the coacervate droplets formed at labeled conversions in PIESA synthesis of $\mathrm{H}_{44} \mathrm{~A}_{97} / \mathrm{E}_{232}$ microdroplets. 


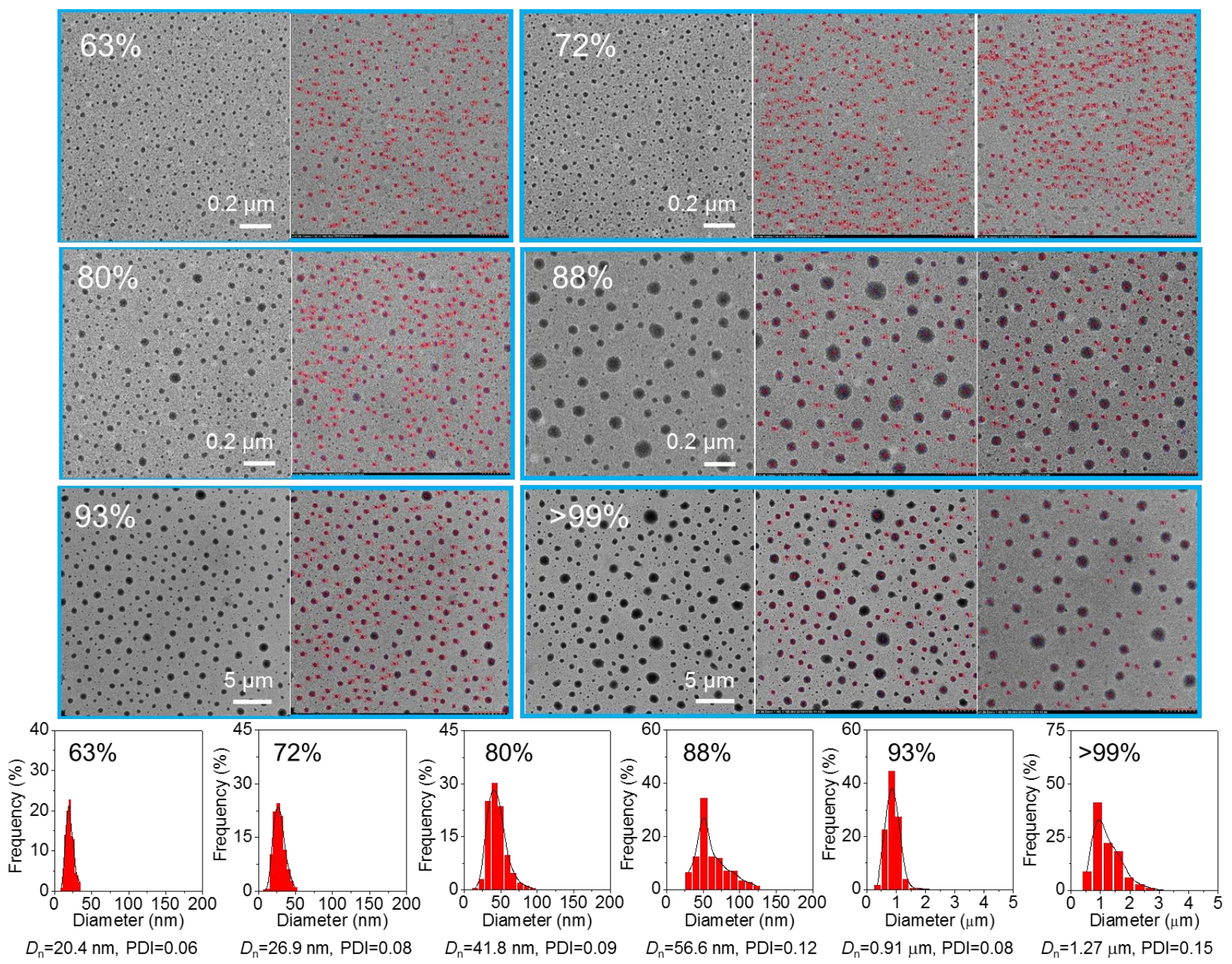

Figure S19. TEM results of freeze-dried droplets formed at labeled conversions during $\mathrm{H}_{44} \mathrm{~A}_{97} / \mathrm{E}_{232}$ synthesis. Herein, $D_{\mathrm{n}}$ is numberaverage diameter of the freeze-dried droplets and PDI is the dispersity in size.

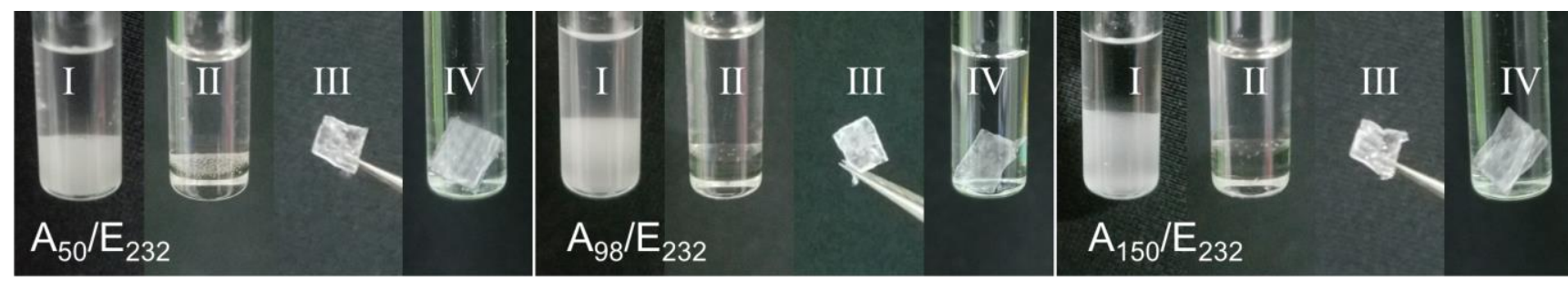

Figure S2o. Photographs to illustrate the deswelling of $A_{x} / E_{232}$ coacervates (I) via replacing polymer-poor phase with equal volume ethanol/water (1:1, w/w) at $\mathrm{pH}$ 2.o. These photographs illustrate that the osmotic deswelling induced the shrinkage of coacervates (II) into solidified glassy PICs (III) that exhibit excellent shape preservation (IV) after immersing into ethanol/water (1:1, w/w). 


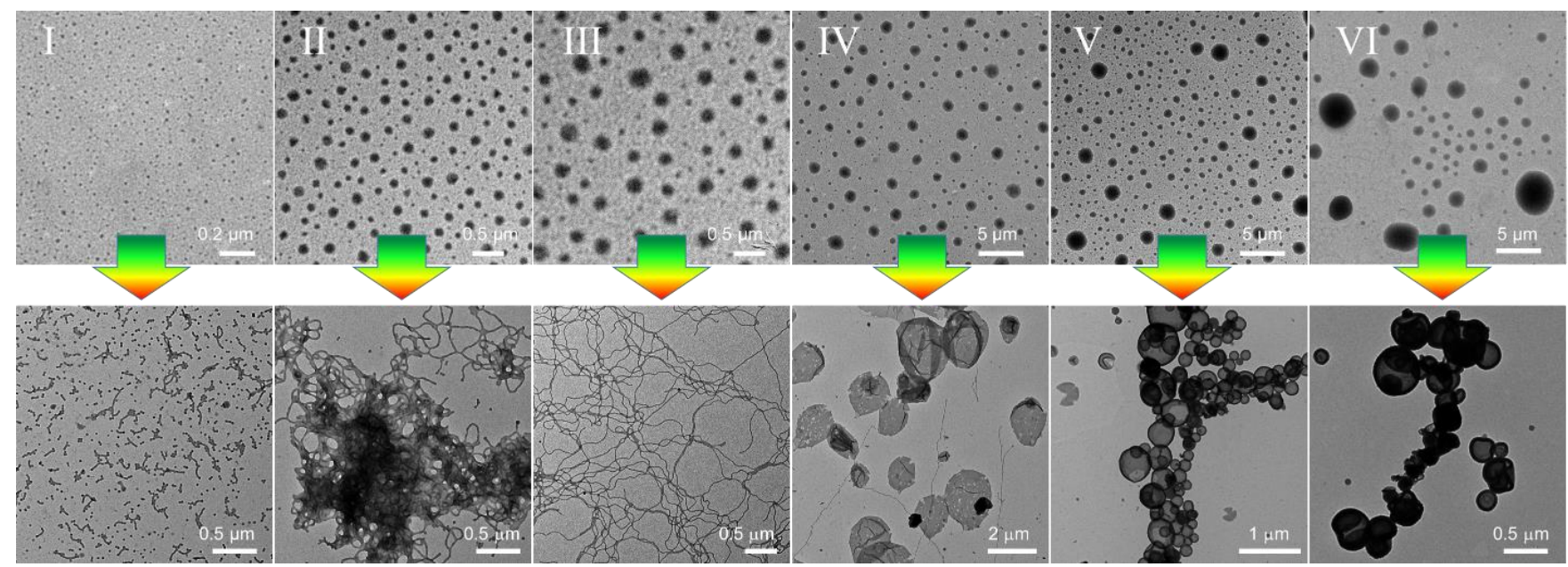

Figure S21. TEM images of (top) freeze-dried $\mathrm{H}_{44} \mathrm{~A}_{x} / \mathrm{E}_{232}$ particles at $x=33$ (I), 58 (II), 77 (III), 97 (IV), 116 (V), and 154 (VI); (bottom) their nanoparticles reassembled by adding ethanol to $2.0 \mathrm{mg} / \mathrm{mL}$ ethanol/water (1:1, w/w), $\mathrm{pH}$ 2.0.
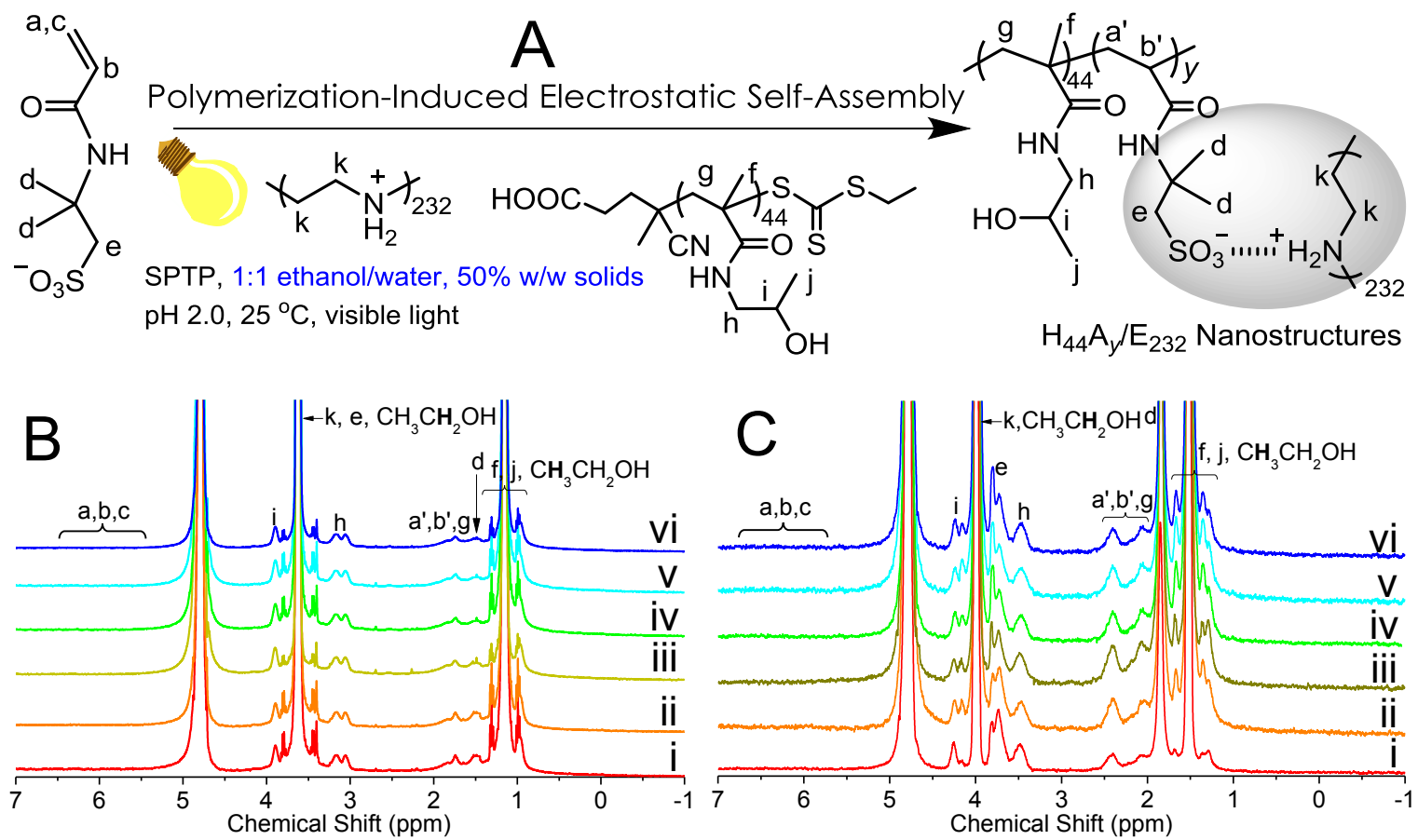

Figure S22. (A) Schematic illustration of PIESA synthesis of nanostructured $\mathrm{H}_{44} \mathrm{~A}_{y} / \mathrm{E}_{232} \mathrm{PICs}$ in ethanol/water (1:1, w/w). ${ }^{1} \mathrm{H}$ NMR spectra of final solutions at $y=30$ (i), 58 (ii), 85 (iii), 125 (iv), 145 (v) and 154 (vi) recorded in (B) $\mathrm{D}_{2} \mathrm{O}$ and (C) $4.5 \mathrm{M} \mathrm{NaCl}$ (pH 2.0 ).
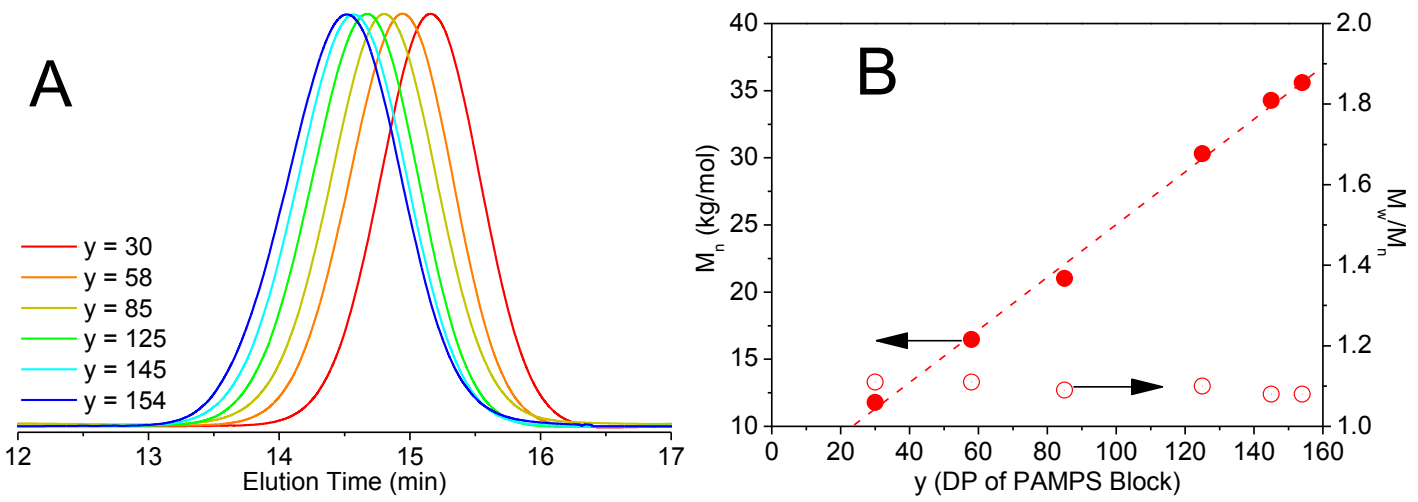

Figure S23. (A) SEC traces of PHPMA 44 -PAMPS block copolymers at labeled $y$ values synthesized by PIESA at $50 \%$ w/w solids in 1:1 ethanol/water. (B) $M_{\mathrm{n}}$ and $Ð\left(M_{\mathrm{w}} / M_{\mathrm{n}}\right)$ as a function of the $y$ value. 

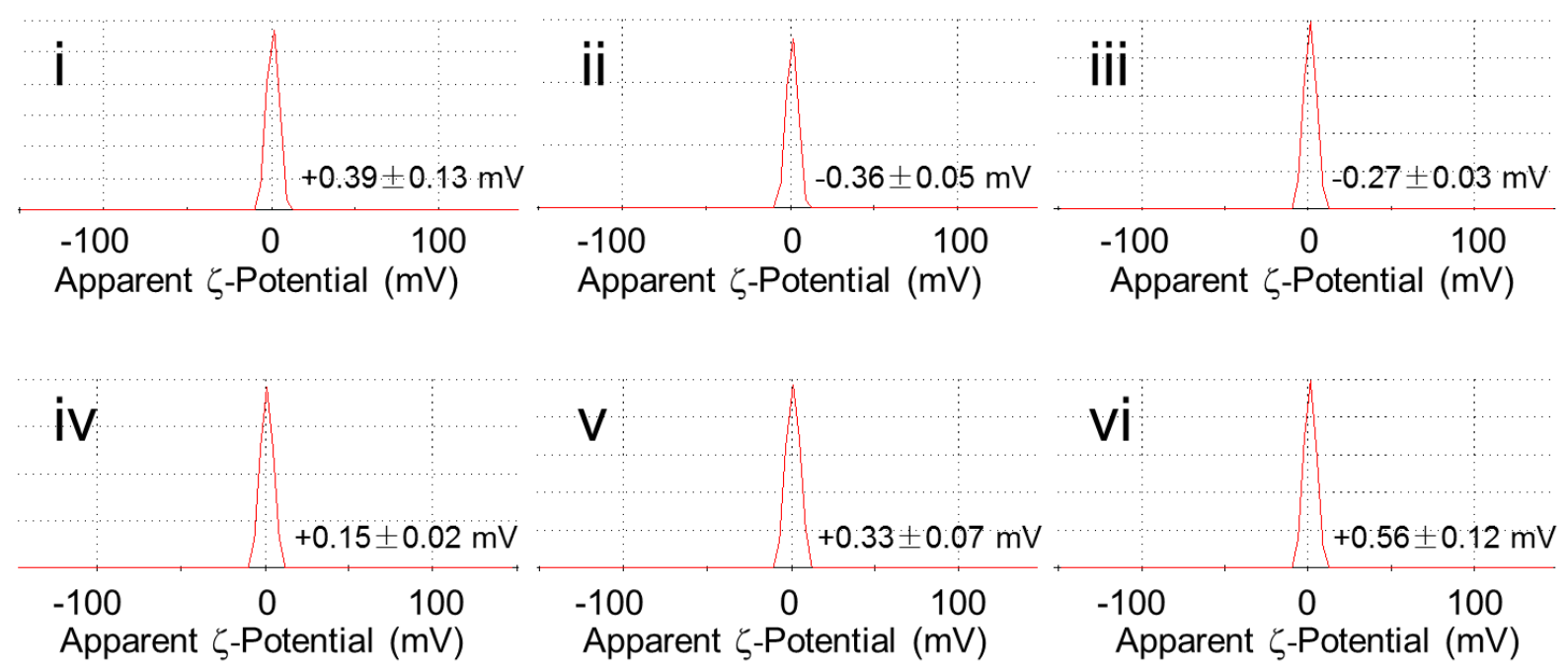

Figure S24. The $\zeta$-potential results of particles of $\mathrm{H}_{44} \mathrm{~A}_{y} / \mathrm{E}_{232}$ at $y=30$ (i), 58 (ii), 85 (iii), 125 (iv), 145 (v), and 154 (vi), synthesized via PIESA at $50 \% \mathrm{w} / \mathrm{w}$ solids in 1:1 ethanol/water, recorded at $2.0 \mathrm{mg} / \mathrm{mL}$ in ethanol/water $(\mathrm{pH} 2.0)$.

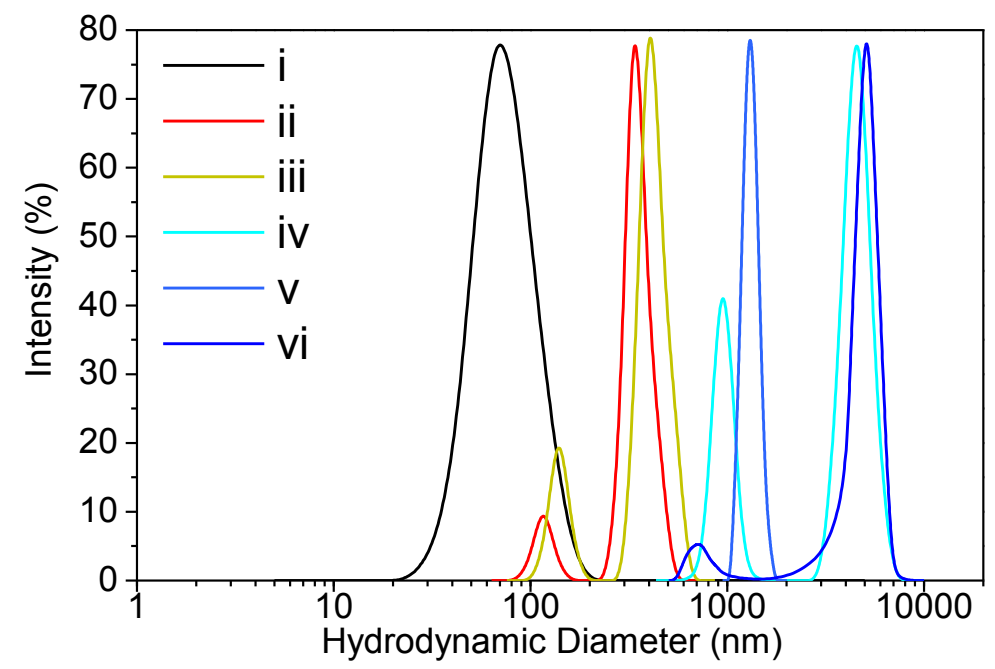

Figure S25. DLS diameter profiles of $\mathrm{H}_{44} \mathrm{~A}_{y} / \mathrm{E}_{232}$ particles at $y=30$ (i), 58 (ii), 85 (iii), 125 (iv), 145 (v), and 154 (vi), synthesized by PIESA at 50\% w/w solids in 1:1 ethanol/water, recorded at $2.0 \mathrm{mg} / \mathrm{mL}$ in ethanol/water at $\mathrm{pH}$ 2.0. 

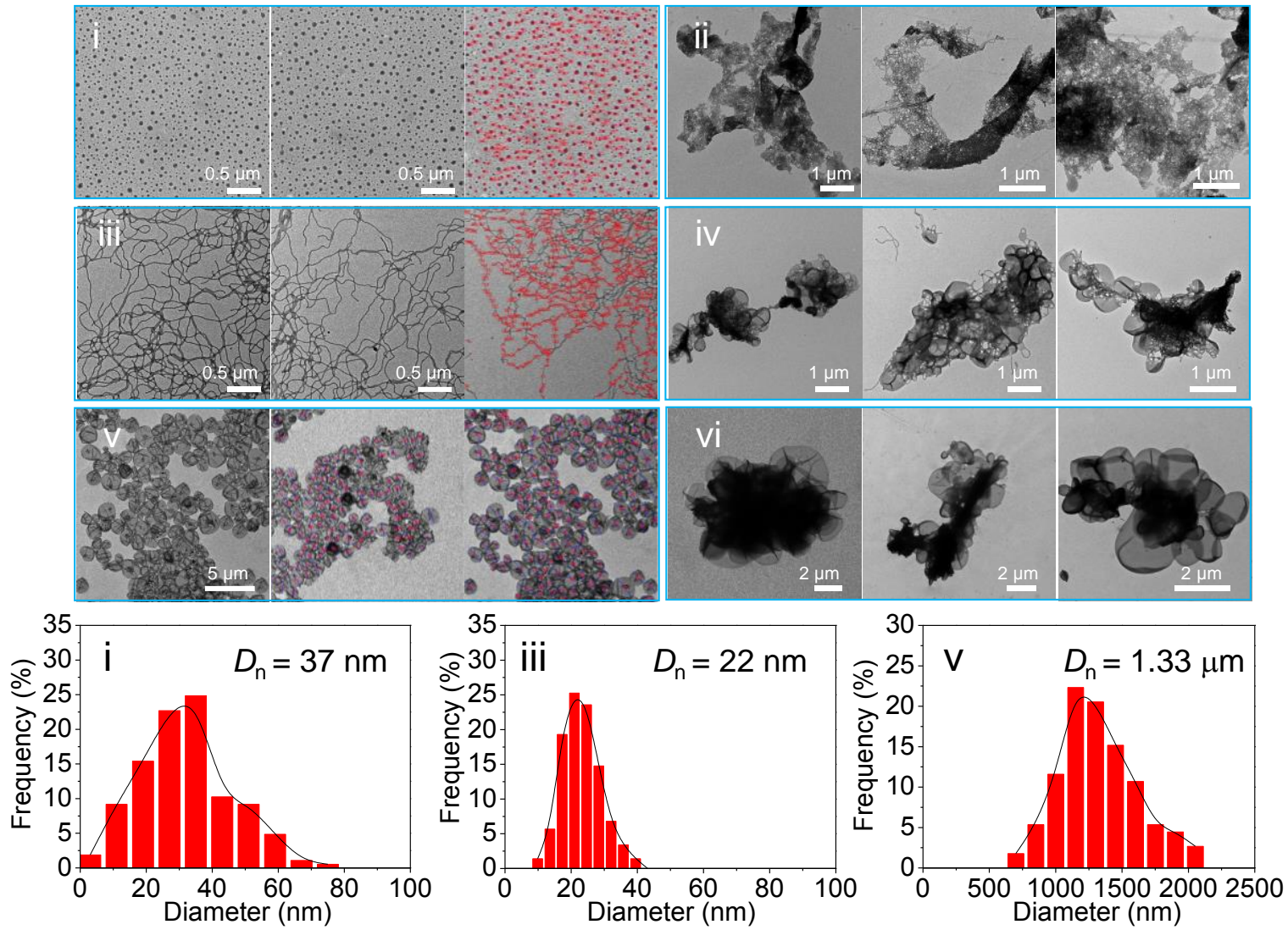

Figure S26. TEM images and statistic results of freeze-dried particles of $\mathrm{H}_{44} \mathrm{~A}_{y} / \mathrm{E}_{232}$ at $y=30$ (i), 58 (ii), 85 (iii), 125 (iv), 145 (v), and 154 (vi) synthesized by PIESA at 50\% w/w solids in 1:1 ethanol/water.

\section{Reference:}

(1) Ding, Y.; Cai, M.; Cui, Z.; Huang, L.; Wang, L.; Lu, X.; Cai, Y. Synthesis of Low-Dimensional Polyion Complex Nanomaterials via Polymerization-Induced Electrostatic Self-Assembly. Angew. Chem. Int. Ed. 2018, 57, 1053-1056.

(2) Jesson, C. P.; Pearce, C. M.; Simon, H.; Werner, A.; Cunningham, V. J.; Lovett, J. R.; Smallridge, M. J.; Warren, N. J.; Armes, S. P. $\mathrm{H}_{2} \mathrm{O}_{2}$ Enables Convenient Removal of RAFT End-Groups from Block Copolymer Nano-Objects Prepared via Polymerization-Induced SelfAssembly in Water. Macromolecules 2017, 50, 182-191.

(3) Bronstert, B.; Henne, A.; Hesse, A.; Jacobi, M.; Wallbillich, G., Acylphosphine Compounds and Their Use as Photoinitiators. U.S. Patent 4,719,297: 1988.

(4) Choosakoonkriang, S.; Lobo, B. A.; Koe, G. S.; Koe, J. G.; Middaugh, C. R. Biophysical Characterization of PEI/DNA Complexes. J. Pharm. Sci. 2003, 92, 1710-1722.

\section{Supplementary Video-S1. avi}

This movie records the real time moving of electrically neutral $\mathrm{H}_{44} \mathrm{~A}_{97} / \mathrm{E}_{232}$ microdroplets $(0.5 \mathrm{mg} / \mathrm{mL} \mathrm{in} \mathrm{water} \mathrm{at} \mathrm{pH} 2.0)$. The dynamic/tentative processes involving collision, coalescence and fission of fluidic complex coacervate microdroplets over time provide an unambiguous evidence of the formation of viscous complex coacervate microdroplets.

\section{Supplementary Video-S2. avi}

This movie records the moving microdroplets synthesized at $>99 \%$ conversion during PIESA kinetic studies, in which the dispersion was diluted to $0.5 \mathrm{mg} / \mathrm{mL}$ in water at $\mathrm{pH}$ 2.0. The formation of fluidic coacervate microdroplets was confirmed by the dynamic processes involving collision, coalescence and fission over time as observed from this movie. These results demonstrate that electrical neutralization can lead to a sharp coalescence of nanodroplets to coacervate microdroplets. 